\title{
Regulation and Reform of Rating Agencies in the European Union: An Insurance Industry Perspective
}

\author{
Anja Theis* and Michael Wolgast \\ Economics Department, German Insurance Association (GDV), Wilhelmstr. 43/43 G, 10117 Berlin, \\ Germany. \\ Emails: a.theis@gdv.de; m.wolgast@gdv.de \\ *Corresponding author
}

This article investigates the current discussion on the regulatory framework for credit rating agencies (CRAs) from the perspective of the insurance industry, focusing on the European Union. It becomes apparent that the new European system of regulation and supervision of CRAs conforms well to general principles of economic theory and can be expected to resolve many issues of concern. In contrast, some of the additional policy options currently discussed in Europe could involve substantial costs and risks for market participants and the financial system without contributing further to the objectives of CRA reform.

The Geneva Papers (2012) 37, 47-76. doi:10.1057/gpp.2011.33

Keywords: credit rating agencies; financial regulation; insurer ratings

\section{Introduction}

The poor quality of ratings of mortgage-backed U.S. securities and the resulting loss of confidence in the assessments provided by credit rating agencies (CRAs) are widely seen as one major contributor to the financial crisis starting in 2007, even though there are many other origins to that crisis. In the course of the ongoing Euro debt crisis or in the context of the downgrading of the United States by one major rating agency, CRAs have again somewhat superficially been blamed, for example, by some politicians for inappropriate rating decisions that exacerbated financial market turbulence.

For both reasons, it is hardly surprising that the role of CRAs continues to be one prominent aspect of the broad discussion that emerged in the aftermath of the financial crisis on necessary reforms in the financial system. Major reforms for CRAs have already been adopted, and even more fundamental reforms are currently under discussion in the European Union and elsewhere. For the insurance industry, the developments in the field of CRAs are of great importance - not only because of their effects on the financial markets in general, but also because of their direct impact on the insurance business.

Credit rating agencies play a unique role in the financial system. Their independent credit assessments substantially reduce informational asymmetries and information costs, thus reducing barriers in accessing the capital markets and promoting market liquidity, and bringing about a much more efficient financial system. And even though 
to some extent such information services for market participants are also provided by other information intermediaries (e.g. equity or fixed income analysts at investment banks), the CRAs' value added cannot easily be dispensed with.

Moreover, CRAs have also assumed an important "certification function" since their ratings are widely used not only as a reference point in financial regulation, but also in private contracts. Therefore, high quality standards in the rating business and the provision of reliable ratings are of vital importance for the efficiency and stability of the financial system. At the same time, in addition to earlier concerns, certain limitations and shortcomings in CRAs' activities and ratings have by now become apparent, and the impression is that the market process alone cannot ensure that CRAs adequately fulfil their function in the financial system.

The particularities and deficiencies of the rating market and possible reform measures have already been extensively covered in the academic literature ${ }^{1}$ and numerous official reports. ${ }^{2}$ There is also a vast body of literature providing quantitative analyses on the quality of ratings and their impact on the financial markets. ${ }^{3}$

However, as yet there are few studies dealing with the impact of the regulatory measures recently adopted and the current proposals for further measures in the political sphere. ${ }^{4}$ For the European Union, the present article discusses these issues both from an empirical and a theoretical point of view, focusing on an insurance industry perspective. In particular, both the regulatory reforms already agreed upon in Europe and the extensive ongoing discussion on further measures in the European Union are being discussed, and the suitability of the various (potential) policy measures to contribute to the objectives of CRA reform is examined.

The starting point is an illustration of the importance of CRAs for insurance companies, including some empirical evidence from the German insurance market. In the following section, major issues of concern that became apparent with respect to CRAs' activities are identified. A short overview and impact analysis of regulatory measures already agreed on follows. The remainder of the article is dedicated to the current European discussion on further measures in the field of CRAs. In particular, the ideas and proposals put up for discussion by the European Commission in its consultation on CRAs of November $2010^{5}$ are examined and put into perspective. Finally, we provide some conclusions and recommendations for further action.

\section{The relevance of ratings for insurers: Some evidence from the German market}

The activities of CRAs are highly relevant for the insurance industry. From the point of view of an individual insurer, the largest impact of rating activities results from

\footnotetext{
${ }^{1}$ For example Partnoy (2001, 2006), White (2002, 2010), Hill (2004), Dittrich (2007), Forster (2008), Coffee (2010).

${ }^{2}$ For example Senate Committee on Governmental Affairs (2002), SEC (2008), IOSCO (2008a), de Larosière Group (2009).

${ }^{3}$ For example Gonzales et al. (2004), IMF (2010, Chapter III).

${ }^{4}$ One counterexample is de Haan and Amtenbrink (2011).

${ }^{5}$ European Commission (2010a).
} 
insurers being rated by CRAs in their role as so-called rated entities. ${ }^{6}$ Even though an assessment of the quality and accuracy of insurer ratings or of their value added for market participants is beyond the scope of this work, as a matter of fact most insurers rely on CRAs for confirmation of their financial soundness. Therefore, CRAs' assessments have become an important constraint on corporate management in the insurance industry.

A rating is indispensable whenever an insurer wants to tap the financial markets to meet capital needs by issuing equity or securities. In addition, even insurers that do not rely on financial markets, meeting their funding or capital needs entirely from premium turnover or retained earnings, often feel the need to procure an insurer financial strength (IFS) rating in spite of substantial fees involved and the need to expend time and effort in order to satisfy the CRA's vast information requirements. The main reason here is that IFS ratings can have a strong impact on an insurer's competitive position.

When contracting with reinsurance companies, primary insurers typically look at reinsurers' financial strength ratings. In primary insurance an increasing number of intermediaries and policyholders also draw on ratings when advising on or taking out insurance, especially in life or industrial insurance. And even if an individual insurer does not see any need to order a solicited rating, it may well be confronted with the market implications of CRAs' assessments being subject to an unsolicited rating. Traditionally, unsolicited insurer ratings have been quite common. For example, in 2005, Fitch assigned a new type of unsolicited ratings (so-called quantitative IFS ratings or Q-ratings) to 136 German insurers, mainly small and mid-sized insurance companies many of which did not have any dealings with a CRA before.

In the market for insurer ratings, there are currently four global players. Besides the three major CRAs known from any other rating activity-Standard \& Poor's, Moody's and Fitch - there is A.M. Best, a specialised CRA for the insurance sector with particular importance for the U.S. market and for international (re)insurance groups that is competing on equal terms with the other three. Measured by the absolute number of ratings of insurance companies - including all types of ratingsStandard \& Poor's has the highest number of insurer ratings (about 8,200), followed by A.M. Best (5,062), Moody's $(4,540)$ and Fitch $(1,675) .^{7}$

For the German insurance industry, Standard \& Poor's is again the most important CRA with 76 IFS ratings, compared to 52 IFS ratings by Fitch, 24 IFS ratings by Moody's and 23 IFS ratings by A.M. Best (see Table 1).

In addition, in the German market, Assekurata, a national CRA specialised on insurer ratings, also plays an important role. Founded only in 1996, Assekurata by now has gained broad acceptance in the insurance market and currently assigns ratings to 42 German insurance companies. Assekurata's ratings are somewhat different in methodology as its main clientele are intermediaries and policyholders, in particular. However, as Assekurata has been granted registration under the new European

\footnotetext{
${ }^{6}$ For a broad overview of the relevance of insurer ratings cf. Swiss Re (2003).

${ }^{7}$ Data according to the respective form for registration as a Nationally Recognized Statistical Rating Organization (NRSRO) in the U.S. as provided on CRAs' websites as of June 2011.
} 
Table 1 Number of IFS ratings for German insurers

\begin{tabular}{|c|c|c|c|c|c|}
\hline & Overall & Life insurers & Health insurers & $P \& C$ insurers & Re-insurers \\
\hline \multicolumn{6}{|c|}{ Standard \& Poor's } \\
\hline Solicited & 69 & 24 & 8 & 28 & 9 \\
\hline Unsolicited & 7 & 0 & 0 & 7 & 0 \\
\hline \multicolumn{6}{|l|}{ Fitch } \\
\hline Solicited & 47 & 19 & 7 & 18 & 3 \\
\hline Unsolicited & 5 & 1 & 1 & 1 & 2 \\
\hline \multicolumn{6}{|l|}{ Assekurata } \\
\hline Solicited & 42 & 20 & 12 & 10 & 0 \\
\hline \multicolumn{6}{|l|}{ Moody's } \\
\hline Solicited & 24 & 10 & 3 & 9 & 2 \\
\hline \multicolumn{6}{|l|}{ A.M. Best } \\
\hline Solicited & 23 & 5 & 2 & 9 & 7 \\
\hline
\end{tabular}

Source: Data collected from the relevant CRA websites as of June 2011 by the authors.

regulatory framework in August 2011, its ratings might shortly be used for regulatory purposes as well. ${ }^{8}$

The extent to which an insurer relies on insurer ratings depends on various factors, in particular, legal form, business lines, distribution channels and overall strategy. In June 2011, of the 20 largest insurance groups in Germany, 18 groups had commissioned at least one solicited rating for their insurance companies (see Table 2). While seven of these insurance groups had a business relationship with only one CRA, three groups had procured a rating from two CRAs, six from three CRAs, one from four CRAs and one from all five CRAs active in the market for German insurer ratings. Rating mandates by insurance groups often cover all the individual insurers that are part of the group, but it is also not unusual that a rating mandate is limited to selected companies in the group.

Broadening the picture from insurance groups to individual insurance companies and taking into account all German insurers, the 205 solicited IFS ratings listed in Table 1 were assigned to 121 insurers only, implying that many insurers had commissioned two or more IFS ratings. Whereas 71 insurance companies had only one solicited rating, 25 insurers had procured two ratings, 17 insurers three ratings, seven insurers four ratings and one insurer had five ratings. Smaller and mid-sized insurers

\footnotetext{
${ }^{8}$ In addition to CRAs' assessments on creditworthiness, there are a multitude of further assessments of insurance companies or insurance products by other providers of financial information or trade and consumer journals. Although these assessments can be highly influential in the insurance market, they are generally not considered as genuine ratings and therefore not covered by the current discussion and regulatory initiatives with respect to CRAs. For an overview of ratings and further assessments of insurers in the German market cf. Assekurata (2006).
} 
Table 2 Solicited ratings mandated by the 20 largest groups in Germany ${ }^{\mathrm{a}}$

\begin{tabular}{|c|c|c|c|c|c|}
\hline & $S \& P$ & Fitch & Assekurata & Moody's & A.M. Best \\
\hline Allianz & $\mathrm{x}$ & & & $\mathrm{x}$ & $\mathrm{x}$ \\
\hline Generali & $\mathrm{x}$ & $\mathrm{x}$ & $\mathrm{x}$ & $\mathrm{x}$ & $\mathrm{x}$ \\
\hline Ergo & $\mathrm{x}$ & $\mathrm{x}$ & & $\mathrm{x}$ & $\mathrm{x}$ \\
\hline Axa & $\mathrm{x}$ & $\mathrm{x}$ & & $\mathrm{x}$ & \\
\hline Talanx & $\mathrm{x}$ & & $\mathrm{x}$ & & $\mathrm{x}$ \\
\hline $\mathrm{R}+\mathrm{V}$ & $\mathrm{x}$ & $\mathrm{x}$ & & & \\
\hline Debeka & & & $\mathrm{x}$ & & \\
\hline Zurich & & & & $\mathrm{x}$ & \\
\hline Versicherungskammer Bayern & $\mathrm{X}$ & & & & \\
\hline Signal Iduna & & & $\mathrm{x}$ & & \\
\hline HUK-Coburg & & & $\mathrm{x}$ & & \\
\hline Gothaer & $\mathrm{x}$ & $\mathrm{X}$ & $\mathrm{x}$ & & \\
\hline Wüstenrot \& Württembergische & $\mathrm{x}$ & $\mathrm{x}$ & & & \\
\hline Nürnberger & $\mathrm{x}$ & $\mathrm{x}$ & $\mathrm{x}$ & & \\
\hline Provinzial Nordwest & & $\mathrm{x}$ & & & \\
\hline SV SparkassenVersicherung & & & & & \\
\hline Alte Leipziger/Hallesche & $\mathrm{x}$ & $\mathrm{X}$ & $\mathrm{x}$ & & \\
\hline Continentale & & & & & \\
\hline LVM & & & $\mathrm{X}$ & & \\
\hline VHV & $\mathrm{X}$ & & $\mathrm{x}$ & & \\
\hline
\end{tabular}

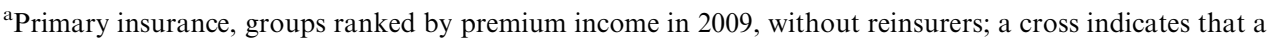
solicited rating by the respective CRA has been ordered for at least one insurance company in the group. Source: Data collected from the relevant CRA websites as of June 2011 by the authors.

also often solicit ratings, though there are quite a number of insurers or insurance groups which do not consider a rating as necessary.

With respect to the selection of CRAs, there is no typical combination. Almost any conceivable mixture of CRAs can be observed in the market. What is evident, though, is that combinations between ratings by Assekurata and other CRAs are less common than combinations of ratings of the four international CRAs. This can be ascribed to the somewhat different focus of Assekurata's ratings, which, from the viewpoint of the insurance company, might partly serve different goals than IFS ratings by the other four CRAs.

Over the last two years, the rating reports published by the CRAs show that the number of ratings for German insurance companies has decreased. One reason for this is that against the background of the regulatory changes in the rating market, the vast majority of unsolicited ratings were withdrawn by the CRAs. In addition, several insurance companies have decided not to renew (some of) their rating mandates. This is partly due to cost saving measures in a tighter insurance market. However, one factor might also be that insurers that do not need a rating for capital market purposes might feel less inclined to pay for a rating during times of crisis when rating grades tend to decrease on average due to general market conditions.

Apart from their role as rated entities, insurers are confronted with the activities of $C R A s$ in their role as institutional investors. Though insurance companies are usually not allowed to rely "blindly" on external ratings - for example, German insurers are always 
required to assess the risks associated with any investment on an ongoing basis-CRAs' ratings are still a very important tool even for insurers that use sophisticated internal models, for example for benchmarking purposes. In addition, ratings are also used to assess counterparty risks, in particular with respect to reinsurance companies.

Over the last few years, CRAs' ratings have also increasingly been embedded in insurance regulation. For example, the German supervisory authority uses external ratings as a proxy for asset risk in stress testing. Current plans for the new Solvency II framework also envisage some drawing on external ratings, for example in the standard formula. In addition, as a protection against a loss of the counterparty's creditworthiness, (re)insurance contracts sometimes include a rating trigger, for example in the form of a special cancellation clause that becomes effective in case of a rating downgrade below a certain threshold.

Because of the integral role CRAs' ratings have assumed for the insurance industry, insurers depend crucially on high standards in the rating process and the reliability and quality of the ratings issued by the CRAs. More generally, insurers also rely on a smooth functioning of financial markets and the stability of the financial system as a whole, which might also profit from high quality standards in CRAs' activities.

\section{Issues of concern}

An effective credit rating industry that provides the financial system with reliable credit assessments has become a highly relevant element for the efficient functioning of modern financial markets. And indeed, most of the time, CRAs seem to have provided an appropriate service, by and large satisfying the expectations of market participants and supervisory authorities. However, there were some prominent episodes of (alleged) failures in CRAs' assessments in times of crisis (e.g. the Asian financial crisis 1997/1998, Enron and Parmalat 2001/2003 or the subprime crisis 2007).

More importantly, shortcomings in CRAs' activities had also become apparent in the normal course of CRAs' business, for example with respect to the ratings of German insurers. While, in general, there has been a good working relationship between the German insurance industry and CRAs, over the past years, a number of problematic incidences occurred, and there had long been some unease on the part of many insurance companies regarding the business conduct of the (until quite recently mostly unregulated) CRAs.

The most important issues of concern from the point of view of the German insurance industry were as follows:

1. Ratings must be of high quality and integrity and conflicts of interest inherent in the business model of CRAs are to be avoided entirely or must at least be adequately managed and disclosed. In contrast, a CRA's business interest could be in conflict with the full objectivity of the rating process if there is no clear separation between the rating business and CRAs' advisory business or between rating analysts carrying out the actual assessments and business developers being involved in fee negotiations. In addition, concerning the quality of ratings, it seemed from time to time that CRAs' resources and capacities - in particular the number and qualification levels of insurance rating analysts - were not in line with the specific requirements of 
insurer ratings, for example regarding special know-how with respect to national legal frameworks, actuarial risks and group structures.

With respect to the quality of ratings it also seemed important that minimum standards of interaction with rated entities were adhered to, for example in the case of unsolicited ratings. Here, a procedure of prior notification of rated entities giving them the opportunity to minimise factual errors on the side of CRAs was called for. In addition, adequate complaint management procedures could provide an effective instrument to improve on the quality of ratings.

2. In order to allow market participants to assess the quality of a rating and its potential limitations and to decide on the suitability of its use for their purposes, full transparency of rating methodologies and especially of the respective type of rating seems crucial. For this, the main features of a rating methodology must be published so that rating users can assess the "philosophy" of a certain rating. This applies all the more in case of major methodological changes.

In addition, rating users should immediately be able to recognise whether a rating was solicited or unsolicited and whether the rated entity participated in the rating process and provided internal information to the CRA. Also, if internal information is provided by the issuer in the case of an unsolicited rating, the confidentiality of that information should be guaranteed.

3. In public statements or rating reports, assessments should be displayed in an accurate and appropriate way; exaggerated remarks aimed at increasing publicity should be avoided.

Interestingly, most of these issues of concern for the German insurance industry corresponded to the general discussion on CRAs that fully emerged only at a later stage. For example, the inferior quality of ratings of mortgage-backed U.S. securities could to some extent be explained in terms of conflicts of interest and insufficient resources for the rating and monitoring process. The lack of transparency of rating methodologies has also been widely criticised elsewhere.

Still, in light of the experience of the recent financial crisis, criticism of CRAs has become much broader, in particular in the political sphere, but quite a number of academics also have come out in favour of fundamental reform. For example, the lack of competition between CRAs and the dominance of a few "Anglo-Saxon" global agencies is often deplored. There is also widespread criticism regarding the prevailing issuer-pays business model of CRAs, which is sometimes seen as irrevocably tainted by conflicts of interest.

Besides concerns with respect to the quality of CRAs' activities and their ratings, the extent of the use of ratings by market participants and for regulatory purposes is being scrutinised under the heading of "overreliance" on CRAs' assessments. Indeed-at least prior to the financial crisis of 2008-many market participants and even regulators had in effect "outsourced" their own risk assessment to CRAs and often used ratings without taking their limitations into account.

The mechanistic use of ratings by a large number of market participants also constituted an enormous systemic risk as rating changes could have highly procyclical effects and trigger major market developments, which could be seen in the course of the rating downgrades during the subprime crisis or the euro debt crisis. 
Therefore, in addition to the issues of concern from the perspective of individual market participants there are also important macroprudential issues of concern with respect to the effects of ratings on the stability of the financial system as a whole. During the subprime crisis and again in the context of the current sovereign debt crisis in Europe a major issue in this regard has also been the concern that the timing and communication of rating changes may have aggravated the crises. ${ }^{9}$

Here, it has become apparent that market participants and regulators are subject to conflicting objectives with respect to ratings, which might be difficult to resolve: On the one hand, it is widely seen as a major advantage of ratings that they aim at stability throughout the cycle and show much less volatility than most other risk measures. At the same time, timely rating adjustments are desired.

\section{Regulation of CRAs}

Due to the particularities of the rating business, a consistently high quality of credit ratings and the integrity of the rating process cannot be achieved entirely as a result of competitive forces in the market. Price and service levels, the usual competitive factors, are of subordinate importance in the rating market. What is crucial is reputational competition. Moreover, incentives and opportunities for market participants to scrutinise CRAs and impose sanctions in case of inferior quality of ratings or any misconduct of CRAs are insufficient.

The main reasons for this particular market failure are an oligopolistic market structure, major informational asymmetries between issuers, CRAs and users of ratings, conflicts of interest inherent in any conceivable business model, and the importance of the certification role of ratings, which means that market participants using ratings for regulatory purposes may have little interest in the quality of a rating as long as supervisory authorities are satisfied.

Notwithstanding their vital role in the financial system and the obvious deficiencies of the rating market from the perspective of microeconomic theory, prior to the financial crisis in 2007, CRAs had been subject to hardly any formal regulation or supervision. Whereas other institutions or professions that are comparable in their importance to the financial markets, for example auditors, have had to adhere to a wealth of legal standards or professional codes for a long time, CRAs until quite recently claimed successfully that competition and the need to maintain a good reputation were sufficient to guarantee high professional and quality standards in the provision of rating assessments.

Still, a debate on possible regulatory measures for the rating business had already started in the 1990s. By 2003/2004 a broad international consensus had emerged that some involvement of regulatory authorities in the rating market was needed. The result of this discussion was a "first wave of regulation", starting with a "Statement of

\footnotetext{
${ }^{9}$ Even in the past, supervisory authorities and central banks have often tried to counteract procyclicality in case of rating changes, sometimes on an $a d$ hoc basis. A recent example is the special treatment of Greek sovereign debt after the downgrading of Greece, for example in German insurance supervision or by the ECB.
} 
Principles Regarding the Activities of Credit Rating Agencies" by the International Organization of Securities Commissions (IOSCO) in $2003^{10}$ and - more importantlythe "Code of Conduct Fundamentals for Credit Rating Agencies" published by IOSCO in December 2004. ${ }^{11}$

The objective of the IOSCO Code was to provide a framework for self-regulation by the CRAs by establishing globally accepted minimum standards for CRAs. In the European Union, the IOSCO Code was complemented by a voluntary framework set up in 2005 by the Committee of European Securities Regulators (CESR) to monitor compliance with the Code provisions and annual reports by CESR to the European Commission. $^{12}$

In addition, in Europe, some limited indirect regulation of CRAs' business conduct has been provided by three European Directives: the Market Abuse Directive, the Capital Requirements Directive, which set up the system of recognised External Credit Assessment Institutions (ECAI) as part of Basel II, and the Markets in Financial Instruments Directive.

In the United States, in 2006, with the "Credit Rating Agency Reform Act", a fundamental reform of the informal system of "Nationally Recognized Statistical Rating Organizations" (NRSRO), dating back to the 1970s and designating ratings accepted for regulatory purposes, introduced a formal registration regime and charged the SEC with some oversight of CRAs, entering into force in 2007 even before the outbreak of the subprime crisis. ${ }^{13}$

The first wave of (self-)regulation of CRAs already resulted in substantial efforts by CRAs to improve their business conduct. The major CRAs developed individual codes of conduct that largely incorporated the IOSCO provisions. They also submitted themselves to CESR's monitoring framework. Significant improvements of standards could be observed in the rating market, for example with respect to transparency of methodology, and CRAs increasingly entered into dialogue with market participants.

In the German insurance market, by invoking the new IOSCO provisions, there were two incidents, one of which in the context of a formal complaint, where it proved possible to induce a major CRA (Fitch) to implement significant changes with respect to its business conduct in the case of ratings of German insurers.

However, shortcomings of the new regulatory framework, which relied entirely on self-regulation and (reputational) market pressure, also emerged soon. Several provisions of the IOSCO Code proved insufficient, and it became clear that there was a need for some form of supervisory guidance on the interpretation of some provisions. The most important shortcoming was the lack of any enforcement mechanism. In cases where reputational pressure by market participants and moral suasion by supervisory authorities proved insufficient to ensure adherence to the

${ }^{10} \operatorname{IOSCO}(2003)$.

${ }^{11}$ IOSCO (2004).

12 CESR (2005).

${ }^{13}$ In Europe and at IOSCO level, because of the importance of ratings for the German insurance industry, the GDV has extensively participated in the discussion on the appropriate regulatory framework for CRAs, contributing especially the concrete experience gathered in the German insurance market in this respect, cf. GDV (2004, 2005). 
minimum standards set out in the IOSCO Code, there was no way to induce a CRA to alter its business conduct in the market. ${ }^{14}$

The problematic role of CRAs with respect to the ratings of mortgage-backed U.S. securities, which came to light with the subprime crisis in 2007, and the subsequent discussion on a tighter regulation of CRAs coincided with the earlier observation that the (voluntary) framework of the IOSCO Code had proved insufficient. Soon after, in 2008, IOSCO modified key provisions of its Code, in particular with respect to ratings for structured finance products and with respect to conflicts of interest. ${ }^{15}$

In spring 2009, the Group of Twenty agreed on the need to introduce a registration and supervisory regime for CRAs based on the principles of the IOSCO Code, ${ }^{16}$ initiating a worldwide trend to establish a strict regulatory framework for CRAs- the "second wave of CRA regulation".

In the European Union, the "Regulation on credit rating agencies" (CRA Regulation) was adopted in 2009, which introduced mandatory registration and ongoing supervision for all CRAs operating in Europe. In order to gain registration, CRAs have to comply with strict provisions, in particular with respect to corporate governance, business conduct and transparency. In 2011, as part of the fundamental reform of the supervisory architecture in the European Union, an amendment of the European CRA Regulation was passed, transferring oversight of CRAs from national supervisors to the newly created European Securities and Markets Authority (ESMA, successor of CESR).

In several other countries, regulatory regimes for CRAs were established (Australia, Japan) or - if regulation already existed before - tightened, for example, in the United States. While there are many differences between the regulatory approaches of the European Union and other countries with respect to the detailed design of the regulatory system, the objectives of CRA regulation are very similar, reflecting the internationally accepted principles developed by IOSCO and the long-standing international co-operation of national regulators in view of the global character of CRAs' business. ${ }^{17}$

With the objective of guaranteeing high quality standards in CRAs' activities and more transparency for market participants, the European regulatory framework aims at:

- eliminating conflicts of interest wherever practical (e.g. a ban on advisory services by CRAs to rated entities) and ensuring that CRAs adequately manage and disclose those conflicts of interest that are unavoidable;

- establishing effective internal standards with respect to ensuring ratings quality, for example with respect to methodology and the rating process;

- enforcing greater transparency about ratings (e.g. methodology, type of rating, limitations of a rating, past performance of ratings) and CRAs' activities in general.

\footnotetext{
${ }^{14}$ Cf. GDV (2006, 2007), IOSCO (2007a, b).

${ }^{15} \operatorname{IOSCO}(2008 \mathrm{~b})$.

${ }^{16} \mathrm{G}-20$ (2009).

${ }^{17} \mathrm{Cf}$. IOSCO (2011) for an overview of regulatory approaches to CRAs in selected countries and their consistency with the principles agreed on at IOSCO level.
} 
The regulation is directed at corporate governance and business conduct of CRAs, for example organisational structure, admissible activities, internal policies, business processes and transparency requirements. In contrast, any direct interference of supervisory authorities with rating methodologies or with the rating grades produced by CRAs is explicitly ruled out. ${ }^{18}$

Thus, the assessment of rating methodologies and of the quality and usefulness of specific ratings continues to be left to the competitive forces in the market. This acknowledges the fact that supervisory authorities are in no position to judge the material content of a rating and that rating methodologies and grades can be highly controversial, for example because of professional disagreement. Still, there is good reason to believe that a regulation of standards and procedures might well contribute to the quality of ratings provided by CRAs even though it is difficult to judge upon the quality more directly.

The new European regulatory system has not yet become fully effective, and its introduction has been characterised by several delays. Though CRAs had to apply for registration by September 2010, as of September 2011 only 11 CRAs - and none of the global three-had gained approval. ${ }^{19}$ As of September 2011, ten further CRAs' applications for registration were under consideration. ${ }^{20}$

It certainly was to be expected that the erection of a complex new regulatory framework and supervisory practice from scratch would take quite some time and would be associated with controversial discussions and some readjustment regarding the detailed implementing measures and supervisory standards. However, at the moment it seems unclear when the new system will be fully functional. ${ }^{21}$

Also, the provisions aiming at increasing market pressure on CRAs (e.g. greater transparency with respect to rating performance) will work only slowly and indirectly as successively more information will become available and market participants will learn how to make use of this information in their decision-making. Therefore, at this point, it is not yet possible to assess the full impact of the new regulatory framework for CRAs and in particular whether it will prove sufficient to remedy the shortcomings of the rating market and to ensure an adequate quality of ratings.

However, even today, the positive effects of the new regulatory measures, in combination with market and political pressure on CRAs to draw consequences from the lessons learned during the financial crisis, have already become apparent. For instance, CRAs have taken further extensive measures to improve on their methodologies and internal compliance standards, and the amount of information on rating methodology, procedures and types of rating provided by the CRAs has been extended further significantly.

\footnotetext{
${ }^{18}$ For a more comprehensive overview of the political discussion on regulation of CRAs and the regulatory measures introduced in the first and second wave cf. Utzig (2010).

${ }^{19}$ Cf. ESMA (2011a).

${ }^{20}$ Cf. ESMA (2011b).

${ }^{21}$ Regulation and supervision of CRAs is made even more complex and complicated by interdependencies between different national regulatory systems resulting from the international business model of the global CRAs and the global financial markets, in particular as major CRA reforms were enacted in parallel in the United States and further fundamental reforms are under review there.
} 
With respect to the German insurance industry, a particularly striking example of change is the withdrawal of most unsolicited ratings. While there were almost 200 unsolicited ratings for German insurers back in 2006, some of them based on a very limited database, by June 2011, the number of unsolicited ratings had shrunk to only 12 . For example, in spring 2009, Fitch discontinued its Q-ratings for insurers, and in summer 2009 Standard \& Poor's withdrew most of its unsolicited ratings for German insurers. Also, the general attitude of CRAs towards rated entities, rating users and the general public has improved further and especially their willingness to enter into dialogue has greatly increased due to the new regulatory standards. Further improvements can surely be expected in the future following the full implementation of the regulatory system for CRAs. In addition, in the context of the new CRA Regulation, the European Commission has already been charged with assessing the progress achieved by the new regulatory framework by the end of 2012. This could provide the basis of a well-founded further development of regulation of CRAs, redressing possible shortcomings that might still exist in the regulatory system. In addition, at IOSCO level there is an ongoing exchange of experiences between national regulators, which could also provide an important contribution to the further development of the regulatory regime for CRAs. ${ }^{22}$

\section{Discussion on further measures of reform}

The reforms adopted so far constitute a fundamental change of the regulatory regime for CRAs and will lead to major changes in the rating market and in CRAs' business conduct. However, the progress already achieved has not brought about any pause in the political discussion on CRAs. On the contrary, in the context of the Eurozone sovereign debt crisis, the debate in Europe seems to have intensified, sometimes taking scant account of the changes already mandated for CRAs, for example with respect to dealing with conflicts of interest.

Against this background, as early as June 2010, the European Commission announced its intention to submit further legislative proposals on CRAs. ${ }^{23}$ For this purpose, the European Commission in November 2010 launched a public consultation on the basis of an extensive working document that put numerous ideas and proposals for further reform in the field of CRAs up to discussion. ${ }^{24}$ In response to this consultation paper, the Commission received 93 comments by public authorities, trade associations, CRAs, private companies, academics and others, impressively underlining the importance of the ongoing European reform discussion on ratings and CRAs for a wide range of stakeholders. ${ }^{25}$

In June 2011, after CRAs' sovereign debt rating actions had again provoked strongly worded criticism by European politicians, and the European Parliament had

${ }^{22} \operatorname{IOSCO}(2011)$.

${ }^{23}$ European Commission (2010a).

${ }^{24}$ European Commission (2010b).

${ }^{25}$ The GDV has participated in this consultation process with a comprehensive submission, cf. GDV (2011). 
passed a resolution on CRAs demanding additional measures, ${ }^{26}$ the European Commission reiterated its intention to present legislative proposals on further CRA reform later in 2011.

Like the general discussion on CRAs, the current debate in Europe, as it is reflected in the Commission's consultation paper, can be separated into two broad issues. The first field of discussion concerns the use of ratings by market participants and supervisory authorities and the role of ratings in the financial system. The second comprises the various proposals for changes in the rating market and CRAs' business activities, as, for example, enhancing competition between CRAs, promoting alternative business models, enhancing civil liability of CRAs, or creating special rules for sovereign debt ratings. ${ }^{27}$

There are important interdependencies between these two fields of discussion. For example, if reforms for CRAs result in highly reliable ratings, a broader use of ratings in financial regulation might be justified. On the other hand, the questions that arise with respect to systemic risk resulting from the use of ratings are at least partly independent of the quality of ratings and CRAs' business conduct as herd behaviour of market participants and cliff effects in the financial markets may occur even if ratings are of the highest possible quality.

Proponents of further reform justify the need for additional action with the argument that the introduction of a regulatory framework for CRAs alone is insufficient to ensure the quality of ratings because it does not fundamentally change the market structure or the business model of CRAs. In assessing this claim and the proposed policy measures, the crucial question is whether additional measures can bring about further improvements in the rating market that cannot be achieved by a regulatory framework. In addition, even if further improvements in rating quality were possible, the costs and risks that might be involved with these measures for market participants and the financial system as a whole must be taken into account.

\section{Use of ratings by market participants and supervisory authorities}

In parallel to the debate on the quality of CRAs' assessments and the appropriate regulatory framework, the financial crisis has ignited an intensive discussion on the use of ratings by market participants and in financial regulation, with a view to better ensure financial stability and reduce the systemic risk of rating changes. ${ }^{28}$ Following the stocktaking of the Joint Forum on the use of ratings in the regulatory system finalised in $2009^{29}$ and the adoption of "Principles for reducing reliance on CRA ratings" by the Financial Stability Board in autumn $2010,{ }^{30}$ there is now a broad

\footnotetext{
${ }^{26}$ European Parliament (2011).

${ }^{27}$ Not included in the Commission's consultation are reform proposals that advocate state monitoring of CRAs' methodologies or even a ban on privately provided ratings, for example for sovereign debt issues, as they go beyond the hitherto existing consensus in Europe codified in the CRA Regulation that there must not be any direct state interference in CRAs' methodologies and rating decisions.

${ }^{28}$ For an overview of the issues involved cf. Sy (2009).

29 Joint Forum (2009).

${ }^{30}$ Financial Stability Board (2010).
} 
consensus that an "overreliance" on ratings is to be avoided both in the regulatory system and by market participants.

Currently, national standard-setters and regulators are in the process of reviewing their use of ratings and decide on possible alternative approaches. For example, in the United States, which so far has relied most heavily on ratings for regulatory purposes, the SEC - as charged by the Dodd-Frank Act - is currently in the process of removing references to credit ratings from its rules. ${ }^{31}$

In Europe, a major part of the European Commission's consultation paper is dedicated to appropriate measures to this regard. ${ }^{32}$ The Commission's objective is to promote due diligence and internal risk assessment by market participants and suitable alternatives to the use of ratings in financial regulation. This is certainly worthy of support. Not only would it reduce undue reliance on ratings and systemic risk, it would also contribute to better market monitoring of CRAs' activities and ratings.

In this regard, the new transparency requirements for CRAs introduced with the CRA Regulation can play an important role as they will allow market participants and supervisory authorities a better assessment of external ratings and their suitability for their purposes. In addition, market participants' efforts to avoid undue reliance on external ratings can be expected to strengthen alternative information service providers and induce them to improve their products.

On the other hand, there is a danger that regulators and supervisors try to trim back the use of ratings too much. For example, whereas many of the measures proposed in the European Commission's consultation paper-for example, no exclusive reliance on ratings by market participants, consideration of alternative risk measures in financial regulation - seem reasonable, others are highly debatable.

If it was made mandatory for the financial sector to produce internal ratings for all their assets plus, in the case of structured products, all underlying assets or if the use of more than one external rating was imposed as a general rule, this would involve high costs for financial services firms and would not necessarily contribute to high quality risk assessments. The reason for this is that CRAs' ratings in many cases have substantial advantages compared to the alternatives suggested. Considering the efficiency of the financial system and the quality of risk assessment, it seems neither feasible nor expedient to entirely refrain from referring to external ratings in financial supervision or to severely restrict the use of ratings by market participants.

As specialised information intermediaries, CRAs can reap substantial efficiency gains and build up extensive expertise in assessing creditworthiness which cannot be duplicated by market participants. Even for large and sophisticated financial services companies, CRAs' ratings are an important tool for risk management, for example for benchmarking purposes or in cases where risk exposure is small (e.g. with respect to some issuers) so that it is not viable to build up internal expertise.

CRAs' ratings have important advantages not only compared to full internal risk assessments, but also in comparison with alternative external risk measures. Because of their through-the-cycle view and the qualitative part of their assessment, ratings

\footnotetext{
${ }^{31}$ SEC (2011a).

${ }^{32}$ European Commission (2010a, pp. 5ff).
} 
have the advantage of being less volatile than market-based risk measures. Also, they are based on more information. In addition, assessments by CRAs are always available whereas marked-based risk measures tend to disappear in times of crisis. Compared to other information intermediaries, for example equity analysts, CRAs are subject to a much stronger regulatory framework regarding their business conduct.

Moreover, in order to capture credit risk, it seems sensible to use a variety of risk measures, including CRAs' assessments. What is more, purely quantitative risk assessments will always be insufficient since the qualitative aspects of risk management by financial services firms and, in particular, some flexibility in the approaches of market participants and supervisors are very important in order to reduce procyclicality.

In general, for these reasons, it does not seem possible or adequate to use a catch-all approach with respect to the use of ratings. Instead, it seems more appropriate to reconsider the concrete use of ratings by market participants and in financial regulation on a case-by-case basis. In particular, the respective characteristics of the different financial sectors are very important. For example, the business models of banks and insurers differ widely, implying that ratings play a different role for banks and for insurers and appropriate requirements on the use of ratings could be very different.

For the European insurance industry, with respect to the future use of ratings for regulatory purposes as well as in risk management by insurance companies, the approach taken in the new Solvency II regime will be of crucial importance. The precise design of Solvency II is still being developed, and in this process the possible alternatives to assess credit risks are also under discussion.

Currently, it appears that CRAs' ratings will prove to be an indispensable part of the Solvency II capital requirements approach, at least in the short and mid run, even though, with respect to bank and insurance bonds or counterparty risk in the case of reinsurers, a possible alternative to ratings might be the use of the solvency coverage ratio of banks and (re)insurance companies. In any case, there should be no concurrent European measures on the use of ratings by the insurance industry outside the Solvency II framework in order to avoid inconsistencies and a duplication of efforts.

Regarding internal risk assessments by market participants, an important issue in the discussion that is also referred to in the Commission's consultation paper is the question of market transparency, that is, to what extent market participants should have access to additional information as it is provided to the CRA in the case of solicited ratings. Many proponents of reform ask for more information disclosure by issuers to the market.

A better set of publicly available information could certainly enhance market participants' own risk assessment. However, more transparency is not an end in itself. A full impact assessment and cost-benefit analysis is necessary for any suggested measure. Also, public information can hardly ever replace the assessments provided by CRAs which strongly rely on their specific expertise and close access to issuers, for example, to the management. Even extensive new disclosure requirements might be of little worth if market participants do not have the capacity to digest this information.

At the same time, disclosure requirements can be very costly for rated entities and might even induce some companies to refrain from accessing the capital markets. 
In this respect, it has to be taken into account that while some information can easily be made available to a CRA on a confidential basis, this same information could have an anti-competitive impact if it had to be provided to the market at large, including competitors. Overall, the benefits that would accrue from further transparency requirements might be very limited while the costs of such measures can be substantial.

\section{Enhancing competition between CRAs}

The (alleged) deficiencies in the rating business are also widely attributed to a lack of competition between CRAs. The hope is that new players in the rating market would provide better quality ratings and force the incumbents to increase their quality standards as well. Consequently, there are numerous proposals for enhancing competition between CRAs. In its consultation paper, the European Commission has in particular taken up the widespread demand in the political sphere for the creation of a new European CRA as a public or private entity, ${ }^{33}$ but also the idea that some form of state support for smaller CRAs might be needed in order to lower barriers to entry into the rating market.

All of these measures would constitute direct state intervention in the structure of the rating market which in a market economy can only be justified by substantial welfare improvements that could otherwise not be brought about. The proposals rely on the presumptions that the optimum number of competitors in the rating market cannot be achieved through the market process alone, and that more competition in the rating market is always welfare-enhancing. However, both assumptions can by no means be taken for granted.

The role of market structure and competition in the credit rating market has been extensively discussed in the literature. ${ }^{34}$ It is certainly true that competition in the market for rating services plays an important role and that the rating market is currently highly concentrated so that there are only a very limited number of CRAs competing. Measured by market share, the market at present is clearly dominated by the three "global players": Standard \& Poor's, Moody's and Fitch. ${ }^{35}$ However, there is a multitude of smaller CRAs, some of which are general purpose CRAs like the three "global players"; most of the smaller CRAs limit their business activities to specific geographical areas or industries.

${ }^{33}$ On the initiative of the European Parliament, the CRA Regulation of 2009 charged the European Commission with reporting on a possible creation of a "public Community credit rating agency" (recital 73). The European Parliament's Resolution on CRAs of 2011 (cf. European Parliament 2011) charges the European Commission with conducting "a detailed impact assessment and viability study on the costs, benefits and potential governance structure of a fully independent European Credit Rating Foundation". Some proposals for a European CRA have also suggested to charge the ECB or national central banks in the European Union with the provision of credit ratings. Support for the creation of a new European CRA was also voiced, for example, by the current German government. The idea that a new European CRA should be established in order to contribute to mitigating the inefficiencies in the rating market is not new. It was already discussed in the 1990s when a number of European issuers were unsatisfied with the treatment they received from the dominant (American) CRAs.

${ }^{34}$ For an overview of the issues involved cf. Dittrich (2007).

${ }^{35}$ Their combined market share is usually estimated at over 90 per cent, cf. for example European Commission (2008). However, reliable data on market shares, especially of smaller CRAs, is not available. 
Though it is not possible to determine the exact number of CRAs worldwide, one widely cited estimate is about $70 .{ }^{36}$ Even though the overall impact of the smaller CRAs in terms of global market share might seem low, they do play a significant role in specific markets. One example is the insurance industry: here, A.M. Best is a major player in rating insurance companies, and in Germany, for example, with Assekurata, there also exists an important national rating agency specialised in rating insurers.

From a theoretical viewpoint it is hardly possible to decide whether the current number of CRAs is insufficient or, more generally, what the optimal number of competitors in the rating market would be. Due to the particularities of the rating business, the market mechanism is not fully operative and a higher number of providers does not automatically lead to better market results. Perfect competition between a multitude of hundreds or thousands of CRAs is neither possible nor desirable. Rather, both economic theory and empirical experience strongly indicate that the market structure providing the best possible market result is an oligopoly with comparatively few universal providers and a number of smaller niche players ("natural oligopoly"). ${ }^{37}$ For this, there are mainly two reasons:

- Network effects: The value of ratings for market participants is mainly based on their being easy to understand and widely accepted in the market. A large number of competing CRAs would make high demands on rating users in terms of information processing and hence would greatly reduce the informational advantages of ratings, all the more so as in the future rating users will be increasingly expected not to rely "blindly" on ratings. For rated companies, cooperation with many CRAs or at least monitoring several additional-including unsolicited-ratings would involve considerable additional costs. Therefore, with a view to cost and information efficiency, investors and rated companies are only prepared to take a limited number of CRAs into account in their decisions.

- Economies of scale and scope: The rating business is characterised by high fixed costs. For example, high-quality rating methods and procedural standards have to be developed and continuously maintained, irrespective of the number of rating orders received or the number of subscribers of information services of the agency. The importance of economies of scale and scope entails a systematic trend towards consolidation and concentration in the rating industry. Accordingly, in the past, successful new CRAs were frequently bought up by existing CRAs. ${ }^{38}$

In the past, a structure with very few dominant CRAs complemented by smaller providers of ratings services that mainly concentrate on market niches seems to have emerged in the credit rating market under very different institutional settings. As past experience shows, market entry, though there are substantial (natural) barriers to entry, is possible. For instance, Fitch has succeeded in breaking into the previous duopoly of Standard \& Poor's and Moody's and has subsequently gained a significant

\footnotetext{
${ }^{36}$ Cf. www.defaultrisk.com/rating_agencies.htm. This private website on credit risk issues provides a comprehensive list of CRAs worldwide which is, for example, referred to by the IMF (2010) and the European Commission (2008).

${ }^{37}$ For a discussion of market structure in the rating market cf. White (2002).

${ }^{38}$ For example, Fitch evolved from several mergers between smaller CRAs.
} 
market share in many market segments. Other examples, for example, Assekurata, the German rating agency specialised in insurer ratings, show that new CRAs can establish themselves successfully in specific market segments.

Moreover, there is a strong indication that major changes in the market for CRAs are currently under way. The reputational problems of the existing dominant CRAs in the wake of the financial crisis and the creation of the new regulatory regime in Europe, but also the reform of the U.S. NRSRO system, seem to interact ideally and to promote additional competition in the rating market.

Whereas the "old" NRSRO regime prior to 2007 had a highly anti-competitive impact because there were no formal rules on attaining NRSRO status and the SEC rather arbitrarily designated only a very small number of CRAs as NRSROs, ${ }^{39}$ the new registration systems in Europe and the United States have reduced reputational barriers to market entry for CRAs that fulfil the registration requirements. New CRAs can now gain market acceptance much easier since compliance with high quality standards is guaranteed by the supervisory authorities.

In the European Union, by March 2011, 25 CRAs had applied for registration under the new regulatory system. ${ }^{40}$ The first CRA to gain registration in Europe was Euler Hermes Rating, a German national CRA, which is part of a credit insurance group and can build on a wealth of expertise in risk assessment. In the United States, there are currently ten NRSROs, and with Kroll Bond Ratings a new player that has substantial resources at its command and aims at a global presence has emerged. In Germany, there are ongoing efforts to set up a new full-purpose European CRA which would be privately funded. ${ }^{41}$

In sum, based both on theoretical reasoning and on an analysis of the current market structure, there is little evidence that additional policy measures are needed to promote new competitors. Rather, at present, the potential market for new CRAs is by itself, without any further interference by the state, attracting private capital, leading to new start-ups in that market.

The only caveat for policymakers in this field therefore should be that the regulatory system is flexible enough to allow for different types of CRAs and takes the specific circumstances of smaller CRAs and new market entrants into account. In Europe, the CRA Regulation already provides for some adjustment of regulatory requirements to the specific situation of a CRA according to the principle of proportionality. In the course of implementing the new CRA regulation and establishing supervisory practices it is important now that excessive regulatory costs for new entrants and smaller CRAs are avoided in order to keep entry barriers moderate.

Ultimately, the success of any new CRA on the market will depend on the assessment by market participants whether the new CRA provides additional value compared with existing ratings. Here, by the way, any interference by the state in the process of setting up a new CRA might lead to severe reputational disadvantages and

\footnotetext{
${ }^{39}$ Cf. White (2010, p. 217) for a discussion of the effect of the "old" NRSRO system on competition between CRAs.

${ }^{40}$ BaFin (2011).

${ }^{41}$ Roland Berger Strategy Consultants (2011).
} 
hence negatively impact on the business outlook of that CRA. More generally, a priori it is difficult to say whether and to what extent a demand for further ratings actually exists at all.

A second counter-argument against state intervention with a view to promoting competition in the rating market is that enhanced competition between CRAs has an ambiguous effect on rating quality as competition between CRAs differs markedly from competition in other markets. More competition will very likely have a positive effect on the price of ratings and the quality of CRAs' services - for example with regard to the interaction with rated entities. It could presumably also bring advantages with respect to the innovative strength of the rating industry. However, considering the quality and accuracy of ratings, by far the most important competitive factor is the reputation of a CRA.

An important finding of recent academic papers - based on theoretical models but also on empirical evidence-is that a higher number of competitors tend to weaken the effectiveness of reputational competition as it means that CRAs are no longer sure of their medium- to long-term market position. In this situation short- and medium-term profit and turnover considerations may prevail over longer-term considerations with regard to the reputational costs of a lower quality of ratings. To attract business and to maximise profits it can become worthwhile for a CRA to implicitly compete in providing more favourable grades than are warranted, leading to a so-called rating inflation. ${ }^{42}$

One of the main objectives of the new regulation of CRAs is to counteract these negative effects of competition. But even if a strict regulatory framework eliminates most of the freedom for CRAs to implicitly compete on "favourable" ratings, the incentive persists and is enhanced by a higher degree of competition thus partly countering the effects of regulation. Moreover, an increased number of established CRAs enable market participants to take advantage of different methods and assessments of CRAs to a greater extent by picking those ratings that best comply with their other interests. ${ }^{43}$

This "rating shopping" will even be easier in the future as new regulatory provisions substantially increase transparency about CRAs' methodologies and is potentially blurring the informational content of ratings; the more so, if there is a multitude of CRAs active in the market, the methodologies of which are too manifold to be known by all market participants.

In sum, there might even be a case for a smaller number of and more market power for existing CRAs since this puts the agencies in a better position to guarantee objective and independent ratings and rebuff any pressure for more favourable rating results than are warranted by the financial situation of an issuer. Also, the informational content of existing ratings might then be higher than in a fully competitive situation.

For these reasons, even before considering the potential costs and risks of direct state intervention into the rating market, it seems highly debatable whether there is at

42 The possible negative effect of an additional provider on the functioning of reputational competition is shown by Becker and Milbourn (2009) using the example of successful market entry by Fitch. Similarly, Bolton, Freixas and Shapiro (2009) show that a monopoly CRA can lead to better market results than competition among two CRAs.

43 The possibility of rating inflation even when CRAs are "honest" and want to provide accurate ratings has been shown by Skreta and Veldkamp (2009) for the case of ratings of complex assets. 
all a case for intervention. Moreover, building up or subsidizing new CRAs would require substantial financial resources, ${ }^{44}$ which would either have to be taken out of general government revenues or - as many proposals suggest-levied on rated entities and/or rating users by introducing compulsory measures.

In an extreme case, as suggested by some proponents of a new European CRA, rated entities - such as insurance companies - would be obliged to buy and finance an additional rating from a newly established European CRA without this rating actually being of any use to market participants. Other concepts suggest that all issuers and/or financial market participants should finance the new CRA by means of a special levy or tax on financial transactions. Also, state intervention bears the risk that the resulting ratings might in part be subject to political considerations. Significant inefficiencies in financial markets and competitive disadvantages for European companies would be the consequence.

\section{Promoting alternative business models}

The rating market constitutes a "two-sided market": Since information services of CRAs are valuable for both rated entities and rating users, in theory, both sides of the market could pay for the provision of ratings. Relative payment shares of rated entities and rating users depend on market circumstances and can change over time. ${ }^{45}$ Until the 1970s, CRAs were mainly financed by rating users that subscribed to the CRAs' information services (so-called "subscriber-/investor-pays model"). Since the 1970s CRAs have more and more relied on payments by rated entities (so-called "issuer-pays model"), complemented by some subscriber remuneration. ${ }^{46}$

Over the last few years, the issuer-pays model has increasingly come under attack because of its inherent conflicts of interest: the party hiring and paying the CRA has a great interest in obtaining a favourable rating. Even though this is also the case in other parts of the economy, for example, in the case of auditors or chartered accountants, the issuer-pays model is widely blamed for the problematic role of CRAs with respect to the ratings of U.S. mortgage-backed securities. The close relationship between CRAs and issuers in the market, including the provision of substantial advisory services by CRAs to issuers in addition to rating services, apparently implied that CRAs had a large incentive to provide "favourable" ratings.

Therefore, many proponents of further fundamental reform in the rating market demand that the business model of CRAs must be changed or that alternatives to the issuer-pays model should at least be actively promoted. ${ }^{47}$ There are even voices that want to abolish the issuer-pays model altogether. ${ }^{48}$

${ }^{44}$ Estimates for the cost of setting up a European general purpose CRA usually assume set up costs of at least several hundred million euros.

${ }^{45}$ Cf. Fasten and Hofmann (2010).

${ }^{46}$ Even today, however, some smaller CRAs exclusively use the subscriber-pays model.

${ }^{47}$ Many of these proposals are taken up in the European Commission's consultation paper. In the United States, the Dodd-Frank Act has charged the SEC with a study on possible alternative business models, in particular with respect to ratings of structured finance products.

${ }^{48}$ For example, the European Parliament's Committee on Legal Affairs in its report on the proposed amendment of the CRA Regulation by the European Commission in 2010, argued for a 
As with the measures proposed to enhance competition among CRAs, the crucial questions are again whether a direct government intervention into CRAs' business models would actually improve rating quality beyond the level that can also be achieved by less interventionist regulatory measures, and what the costs and risks involved are. Again, the answers are not trivial, and indeed the political discussion on CRAs' business models often seems to neglect a number of fundamental facts of the rating business.

First of all, due to the very nature of ratings and the inevitable information asymmetries involved, CRAs' business is riddled with conflicts of interest. Moreover, any conceivable remuneration model for CRAs has its own specific conflicts of interest. For example, in an investor-pays model there could be implicit pressure on a CRA to avoid rating downgrades that would result in substantial losses for investors.

Sometimes it is suggested that if CRAs were financed by the state - in the form of a public CRA (so-called "public utility model") or state subsidies to one or more private CRAs - this could help to resolve inherent conflicts of interest in the CRAs' business. However, the state has its own interests; for example under this model there would be a danger of implicit political interference with rating methodologies and results which could impair the credibility of ratings. Conflicts of interest are particularly obvious here with regard to the ratings of public debtors, state-owned companies or private-sector companies which are "national champions".

Moreover, if an existing public authority was tasked with the additional role of public CRA, for example the central bank according to one idea suggested in the European Commission's consultation paper, fundamental conflicts of interest could arise between the different functions of this authority, for example between the provision of accurate credit assessments and ensuring financial stability. ${ }^{49}$

In sum, conflicts of interest inherent in the ratings business can hardly be avoided by resorting to alternative business models. Rather, they have to be dealt with by way of regulation, as is the case in other parts of the economy, for example, with auditors or chartered accountants. ${ }^{50}$ Already, existing regulatory frameworks for CRAs comprise numerous stipulations to avoid or adequately manage and disclose conflicts of interest. One example of this is the ban on advisory services offered by CRAs to rated entities in the new European regulatory system.

Should these provisions prove not to be strict enough - for example, in Europe CRAs are still allowed to provide ancillary services to issuers and rating users which might also involve conflicts of interest-the CRA Regulation could be adjusted accordingly in due course.

ban on any payments for ratings by rated entities or related third parties to CRAs (cf. European Parliament, 2010).

49 The ECB itself, in its comment on the Commission's consultation paper, rejected the idea that it could provide public ratings (ECB 2011, p. 7).

50 The need to deal with this kind of conflict of interest is indeed not limited to the rating business. Rather, it is a common problem known from other sectors of the economy whenever it comes to testifying the quality of a product or the soundness of an economic entity against a fee that is paid by the producer of that product or the relevant economic entity. 
A ban on the issuer-pays model would not only be neither necessary nor sufficient in order to rule out the negative consequences of conflicts of interest in the CRAs' business, it would also bring about severe negative side effects. The business models used by CRAs have a decisive impact on the amount and nature of ratings offered in the market. In particular, the issuer-pays model has distinctive advantages with respect to the availability and the informational content of ratings and therefore in general with respect to the efficiency in the rating market, which is, by the way, one of the reasons for the current dominance of this business model.

In line with the public good character of ratings, ratings that are paid by rated entities are available free of charge to all market participants. In contrast, subscriberpaid ratings are only available to the limited circle of subscribers, reducing market transparency and the potential efficiency gains through ratings. Also, since for many small issuers there might not be enough interest by investors to pay for high quality ratings the overall availability of ratings would probably decrease under a subscriber-/ investor-pays model.

The subscriber-/investor-pays model is also confronted with the problem of potential free riders and information leakage: considering the ease of information dissemination under modern communication standards, it seems difficult to ensure that the ratings are only made available after payment to the CRA. The change in the prevailing business model for CRAs in the 1970s is often ascribed to the fact that only the issuer-pays model could raise the financial resources needed for providing high quality ratings for a vast number of issuers.

In contrast, proponents of a transition to the subscriber-/investor-pays model are often short on details how such a transition could work and what its effects on rating availability and rating quality, including the innovative power of CRAs, would be. ${ }^{51}$ Other reform proposals suggest that in order to build up a viable market for investor-paid ratings, investors who make use of ratings for regulatory purposes should be required to rely on at least one investor-paid rating. ${ }^{52}$ However, this would lead to high additional costs for rating users.

Considering the informational content of individual ratings, the issuer-pays model also provides important advantages. It is not unusual that even unsolicited ratings use some internal information ${ }^{53}$ or are even based on full participation by the rated entity. However, usually the informational base of solicited (issuer-paid) ratings is far better than for unsolicited ratings as CRAs in the case of solicited ratings in general have in-depth access to confidential issuer information, including management interviews. ${ }^{54}$

${ }^{51}$ It is for these reasons that the IMF's assessment is that a return to a general investor-pay subscription model is not realistic (IMF 2010, p. 97). Pagano and Volpin (2009) whose preferred policy solution would be an investor-pays model also regard this model as possibly impractical due to the problems of freeriding and information leakage.

${ }^{52}$ Coffee (2010, pp. 55f).

${ }^{53}$ For example, before assigning an unsolicited rating, Standard \& Poor's has traditionally provided German insurers with a questionnaire so that they can make some internal information available to allow for a higher-quality rating.

54 As De Haan and Amtenbrink (2011, p. 8), point out "While CRAs also provide unsolicited ratings, that is, CRA-initiated ratings, they are generally thought to be less reliable and less accurate than solicited ratings due to the fact that they are based on publicly available data". 
For this reason, issuer-paid solicited ratings are of high value for the functioning of the financial system, notwithstanding the important role of unsolicited ratings, which can be very useful and strengthen competition in the rating market even when based on public information only. ${ }^{55}$

Some proponents of a larger role for unsolicited ratings would like to remedy their informational disadvantage by way of a new kind of information disclosure. The idea is that the (written) information provided to a CRA hired by the rated entity should also be made available to other CRAs that would like to assign an unsolicited rating in the form of a special data room accessible on request if certain conditions are met. ${ }^{56}$

However, there are many doubts with respect to the workability and effectiveness of such new mandatory information disclosures. First of all, it is questionable how far the new data room could contribute to providing high quality unsolicited ratings, as faceto-face contact between CRAs and issuers usually plays a crucial role within the course of the rating process and can hardly be fully substituted by written documents. What is more, issuers are already spending significant resources (financial, but also with respect to managerial and personnel capacity) on supporting the CRAs assigned with preparing credit ratings. They might not be prepared to expend additional resources and might therefore reduce the amount of information they give to the CRA they have hired in order to avoid the disclosure of confidential information to other CRAs.

In the worst case, some issuers could completely refrain from issuing securities if these could not be placed without a rating and a rating would require establishing a data room. All this would involve a loss of efficiency of the financial markets. Moreover, since the model takes the existence of solicited ratings as a prerequisite, it would only be suitable for promoting arbitrarily the market share of unsolicited ratings, and would not be consistent with a complete ban on the issuer-pays model.

With respect to a potential ban on issuer-paid ratings, the public utility model, at first glance, seems to fit well with the public good characteristics of credit ratings and to provide a way to remedy a potential undersupply of high quality ratings. However, apart from the risk of political influence and the question of how the substantial financial resources for the operation of a public CRA could be provided, an important aspect is that there is no indication that the state or public entities are better suited to provide high quality risk assessments, including a continuous further development of ratings, than private market actors.

In addition, a greater role for the state in the provision of rating assessments seems to be somewhat in contradiction with the aim of reducing the importance of

${ }^{55}$ In the past, it could sometimes not be ruled out that unsolicited ratings were used as an acquisition tool by CRAs to induce rated entities to solicit (and pay for) a rating that better represents their creditworthiness. However, at least for the European Union, the new European regulatory framework should ensure that in the future only unsolicited ratings that adhere to high quality standards are assigned.

${ }^{56}$ The European Commission's proposal of 2010 for the amendment of the CRA Regulation (European Commission, 2010c, Articles 8a and 8b) stipulated such an informational disclosure by issuers of structured financial products if certain conditions were met. However, the articles were not included in the regulation finally adopted. A similar provision on information access for CRAs has recently been introduced in the United States, but it is too early to judge the experience. 
ratings in the decision-making of market participants as state-provided or subsidised ratings would probably be considered as quasi-official seals of approval. As a consequence, major liability issues for the state could arise if quality problems occurred at the public CRA.

Other proposals aiming at altering the business model of CRAs and taking account of the public good characteristics of ratings focus on the business relationship between CRAs and issuers or investors paying for the ratings. The basic idea is that rating mandates should be commissioned by a market-wide body, for example a new independent "credit rating agencies board" or an exchange. ${ }^{57}$ The new allocation mechanism could either replace individual rating mandates or it could provide additional ratings, leaving the existing structures of the rating market intact. The intention here is to at least partially disentangle the ultimate payment process from the decision of mandating certain CRAs.

With respect to the design of such an allocation mechanism, numerous questions would have to be answered, for example, how the financial resources for the ratings should be provided and how the body that decides on the assignment of rating mandates should be composed. Even more difficult would be the development of criteria for the selection process of CRAs by the board (e.g. how to maintain competition between CRAs and ensure that those CRAs are selected that provide the best available rating service) ${ }^{58}$ It might also be difficult to retain incentives for continuous innovation in credit ratings.

In any case, implementing this solution would require substantial coordination by market participants and probably massive state intervention, that is, making the use of the new mechanism mandatory. Moreover, the proposal would also imply substantial costs (e.g., if rated entities had to pay for an additional rating provided via the new body) and risks (e.g. uncertainty about market acceptance and quality of the new ratings). Overall, the massive state intervention required to initiate such a fundamental regime change in the rating market does not seem justified, in particular in view of the progress already achieved with the new regulatory framework and in view of the costs and risks of such a transition.

Last but not least, a further proposal for CRA reform is the introduction of performance-related fees for CRAs (the "payment-upon-results model"). ${ }^{59}$ From a theoretical point of view this seems to be an interesting approach in providing financial incentives to CRAs to induce a greater accuracy of ratings. However, on second thought, taking into account the probabilistic nature of ratings, it seems doubtful how such a solution could work in practice as it would be very difficult to design a model that would provide the desired incentives.

${ }^{57}$ The Dodd-Frank Act charges the SEC with examining such a credit rating agencies board for the market of ratings for structured finance products. Mathis, McAndrews and Rochet (2009) advocate the use of exchanges (so called "platform-pays" model).

${ }^{58} \mathrm{Cf}$. Coffee (2010, p. 55) for the problems involved in assigning rating mandates by a credit rating agency board. The complexity and potential difficulties of such a model also become apparent in the consultation paper the SEC published in May 2011 (SEC 2011b).

${ }^{59}$ This has also been suggested by the IMF (2010, p. 97) and Harris (2010). 
For example, there would be substantial problems in the definition of "performance". Default statistics can only serve as a reliable performance indicator over a longer time period and if the number of ratings assigned is large enough to allow for the law of large numbers to become effective. What is more, currently the different rating grades do not correspond to a specific default risk, and default rates are heavily influenced by unforeseeable market developments. In sum, even if it was possible to put such a model in practice, it would make income streams for CRAs incalculable and thus overburden the CRAs with risk.

\section{Enhancing civil liability of CRAs}

A major point of criticism against CRAs has long been their lack of accountability in case of misconduct and poor quality ratings. ${ }^{60}$ Until recently, ratings have mainly been regarded as "opinions". Although in many countries CRAs have always been subject to general civil liability rules, attempts to hold CRAs accountable in court have so far met with little success. Therefore, it is easy to understand that the introduction of financial sanctions for CRAs in order to make them accountable for any misconduct plays an important role in the current reform discussion.

Because of the stochastic nature of ratings and the possibility that real world outcomes seem not to correspond to a rating even if the rating assessment of the probability distribution was actually correct and CRAs had exercised due care in every respect or because of ex-ante adequate model assumptions that prove overly optimistic or pessimistic in retrospect, it seems hardly possible to make CRAs liable for "incorrect" ratings as is sometimes demanded in the political discussion. On the other hand, the basic idea that CRAs should face financial sanctions if they violate regulatory rules and do not adhere to minimum standards in their business conduct seems compelling.

In Europe, such financial sanctions have already been introduced: With the amendment to the European Regulation for CRAs in December 2010, the European Parliament and the European Council agreed on a comprehensive system of fines and periodic penalty payments for infringements of regulatory provisions. Fines for an infringement typically amount to several hundred thousand euros. In the case of periodic penalty payments for continuing rule violations, much higher fines can result.

Economic incentives to comply with regulatory provisions are thus in place already, and, moreover, in case of penalties imposed by the regulatory authorities, there is a direct and predictable correlation between the violation of rules and the financial sanction imposed.

In its consultation paper, the European Commission suggests the additional introduction of a European civil liability scheme in case of CRAs' infringements of the new regulatory rules. However, it is not clear whether this measure could lead to any improvement in the rating market. On the contrary, it might even have negative effects.

\footnotetext{
${ }^{60}$ Cf. for example Partnoy (2006).
} 
72

Civil liability should certainly play a supplementary role with respect to providing financial incentives for a high quality of ratings. However, its impact is much more indirect and involves great uncertainty both for CRAs and market participants as it will usually prove very difficult to decide on the causality of ratings for any loss incurred or to determine the amount of damage caused by the CRA, considering the intricate interrelations in the financial system. ${ }^{61}$

As a consequence of an increased liability regime for CRAs, the costs of ratings could also rise significantly to compensate for increased liability risk, and CRAs could become much more conservative in their business conduct and their ratings, resulting in a reduction in rating availability, less innovation and higher costs of capital. Excessive civil liability could even hamper the very functioning of the CRAs' business and hence the financial system in total, if it proves impossible for CRAs to bear the risk of liability, especially if insurance-based solutions are not available and necessary equity capital cannot be afforded at reasonable cost. ${ }^{62}$

\section{Special rules for sovereign debt ratings}

In the recent euro debt crisis, CRAs have been widely blamed by European politicians for exacerbating the crisis with their rating downgrades for a number of European states which have been deemed ill-timed. Against the background of this political discussion, in its consultation paper, the European Commission puts a number of special provisions for sovereign debt ratings to discussion, which are intended to remedy perceived specific failings with respect to this kind of ratings. ${ }^{63}$

Ideas for reform measures include more information disclosure on sovereign debt ratings by CRAs, a more frequent monitoring of such ratings and an extension of the period of prior notice of rated states about ratings and rating changes. In addition, the Commission raises the question whether the issuer-pays model should be banned for sovereign debt ratings and whether investors should be required to always internally rate public debt.

In the wake of the aggravation of the sovereign debt crisis and the conflict between CRAs and European politicians in summer 2011, even more far-reaching proposals were discussed. For example, the Single Market Commissioner Barnier thought publicly about banning sovereign debt ratings in certain circumstances altogether. ${ }^{64}$

From the viewpoint of economic theory, it is difficult to make a case for special rules for sovereign debt ratings. There are no fundamental differences between sovereign debt ratings and ratings assigned to private issuers with respect to the role of ratings, the value added by CRAs and the alternatives available to market

${ }^{61}$ In the literature, for this reason, there is also some skepticism regarding the effectiveness of the civil liability regime in case of CRAs, cf. for example Hill (2004, p. 45).

${ }^{62}$ In the United States, the limitations of civil liability became apparent in the course of the introduction of the Dodd-Frank Act's new rules which subject CRAs to expert liability if their ratings are included in bond offering documents. This has so far proved unworkable as CRAs felt they could not bear this increased liability risk and restricted the possible use of their ratings.

${ }^{63}$ European Commission (2010b, pp. 14ff).

${ }^{64}$ Barnier (2011). 
participants. ${ }^{65}$ The problems and shortcomings of the rating market are mostly identical for credit assessments involving the public sector and the private sector, for example with respect to conflicts of interest or the risk of market turbulence in case of major rating changes for systemically important (public or private) issuers.

If further measures in addition to the requirements already set out in the new European regulation are considered necessary, these should be discussed for all ratings. In order to guarantee the independence of CRAs and to ensure a high quality of ratings, it seems essential that a preferential treatment of issuers from the public sector and any political interference in the rating process are avoided.

\section{Conclusion}

Given the importance of ratings for the insurance industry, important issues of concern with respect to rating methodologies and especially the business conduct of CRAs had been acutely felt by insurers for a long time. The two waves of regulation brought about by the IOSCO code of conduct fundamentals for CRAs back in 2004 and then-following the experience of the subprime crisis of 2007-by the introduction of a formal regulation and supervision of CRAs in Europe and elsewhere seem to have the potential to resolve many, if not all, deficiencies in the market for credit ratings from the point of view of the insurance industry. This provides a promising example of social and economic progress and policymaking that is in line with the principles of economic theory.

Considering the challenges of setting up a completely new regulatory framework, the crucial task now is to make the new registration and supervision system for CRAs in Europe work as intended, finalising its implementation and establishing appropriate supervisory practices. On the other hand, suggestions for further measures of reform concerning CRAs (an imminent third wave of regulation) in the course of the current political discussion seem much less convincing and in any case premature, as the impact and success of the new European regulatory framework for CRAs so far cannot be fully assessed.

Rather, most of the measures of reform currently under discussion in order to supplement the existing regulatory framework by a third wave of regulation of CRAs could, if put to practice, pose a threat to the very functioning of the business of CRAs or at least imply high additional costs and risks for market participants and thus reduce the efficiency of the financial system.

Since credit ratings will continue to be of crucial importance, if not indispensable, for the insurance industry and the efficient functioning of the financial system more generally, it would be wise if policymakers for the time being largely renounced the proposed measures. Especially, there is no case for direct public intervention with respect to competition, market structure or business models in the rating market.

\footnotetext{
${ }^{65}$ Naturally though, there are substantial differences to private sector issuers with respect to rating methodology, cf. IMF (2010). However, this seems rather irrelevant in this context.
} 
Instead, the focus should be on a proper and efficient implementation of the regulatory provisions already agreed on, including a critical review of the effects of the new CRA Regulation some time after its complete implementation. Moreover, the objective to reduce overreliance on ratings by market participants and in financial regulation and to strengthen risk management capabilities of market participants should be further pursued.

\section{Acknowledgements}

We thank two anonymous reviewers for their comments on an earlier version and Lilli Bombei (German Insurance Association) for her help with the empirical data on insurer ratings in Germany.

\section{References}

Assekurata (2006) Die Bedeutung von Ratings für den deutschen Versicherungsmarkt, Cologne.

Barnier, M. (2011) The new European Securities and Markets Authority: Helping enhance the resilience of financial markets, Speech/11/514 (11 July, Paris).

Becker, B. and Milbourn, T. (2009) Reputation and competition: Evidence from the credit rating industry, Working Paper 09-051, Harvard Business School.

Bolton, P., Freixas, X. and Shapiro, J. (2009) The credit rating game, NBER Working Paper 14712.

Bundesanstalt für Finanzdienstleistungsaufsicht (BaFin) (2011) Jahresbericht 2010, Bonn and Frankfurt a.M.

Coffee, J. (2010) 'Ratings reform: The good, the bad, and the ugly', Note, in OECD Competition Committee, Hearings Competition and credit rating agencies, pp. 39-66.

Committee of European Securities Regulators (CESR) (2005) CESR's dialogue with credit rating agencies to review how the IOSCO code of conduct is being implemented (13 December), reference 05-751.

de Haan, J. and Amtenbrink, F. (2011) Credit rating agencies, DNB Working Paper No 278.

de Larosière Group (2009) Report of the high-level group on financial supervision in the EU, chaired by Jacques de Larosière (25 February, Brussels).

Dittrich, F. (2007) The credit rating industry: Competition and regulation, Dissertation, University of Cologne.

European Central Bank (ECB) (2011) European Commission's public consultation on credit rating agenciesEurosystem reply (February, Frankfurt a. M.).

European Commission (2008) Commission staff working document accompanying the proposal for a regulation of the European Parliament and the council on credit rating agencies, Impact Assessment (COM(2008) 704).

European Commission (2010a) Consultation paper of November 5, 2010 on possible further measures in the field of credit rating agencies (CRAs, Brussels).

European Commission (2010b) Communication of the European Commission to the European Parliament, the Council, the European Economic and Social Committee and the European Central Bank: Regulating financial services for sustainable growth (2 June).

European Commission (2010c) Proposal for a regulation of the European Parliament and of the Council on amending Regulation (EC) No 1060/2009 on credit rating agencies, $\operatorname{COM(2010)~} 289$ final (2 June).

European Parliament (2010) Opinion of the Committee on Legal Affairs for the Committee on Economic and Monetary Affairs on the proposal for a regulation of the European Parliament and of the Council amending Regulation (EC) No 1060/2009 on credit rating agencies, COM(2010)0289-C7-0143/2010-2010/ 0160(COD) (28 October).

European Parliament (2011) European Parliament resolution of 8 June 2011 on credit rating agencies: future perspectives (2010/2302(INI)).

European Securities and Markets Authority (ESMA) (2011a) List of registered and certified credit rating agencies, ESMA/2011/247 (14 September).

European Securities and Markets Authority (ESMA) (2011b) Regulatory technical standards on the information to be provided to ESMA by a credit rating agency in its application for registration and 
certification and for the assessment of its systemic importance, consultation paper, ESMA 2011/302 (19 September).

Fasten, E.R. and Hofmann, D. (2010) Two-sided certificaton: The market for rating agencies, Discussion Paper 2010-007, Humboldt-Universität zu Berlin, SFB 649.

Financial Stability Board (2010) Principles for reducing reliance on CRA ratings (17 October), from www.financialstabilityboard.org.

Forster, J. (2008) The optimal regulation of credit rating agencies, Discussion Paper 2008-14, Department of Economics, University of Munich.

German Insurance Association (GDV) (2004) Public comment on code of conduct fundamentals for credit rating agencies, response to IOSCO's consultation report of October 2004, Berlin.

German Insurance Association (GDV) (2005) Comment on CESR's technical advice to the European Commission on possible measures concerning credit rating agencies, response to CESR's consultation paper of November 2004, Berlin.

German Insurance Association (GDV) (2006) Comments on the day-to-day application of the IOSCO Code by the credit rating agencies (CRAs), response to CESR's questionnaire of 6 July 2006, Berlin.

German Insurance Association (GDV) (2007) Comment on IOSCO's Consultation Report on Implementation of the IOSCO CRA Code, response to IOSCO's consultation report of February 2007, Berlin.

German Insurance Association (GDV) (2011) Comment on the European Commission's public consultation on credit rating agencies of 5 November 2010, Berlin.

Gonzales, F., Haas, S.F., Johannes, R., Persson, M., Toledo, L., Violi, R., Wieland, M. and Zins, C. (2004) Market Dynamics associated with credit ratings: A literature review, Occasional Paper series No 16, ECB.

Group of Twenty (G-20) (2009) Declaration on strengthening the financial system, www.g20.org.

Harris, L. (2010) 'Pay the rating agencies according to results', Financial Times (3 June).

Hill, C. (2004) 'Regulating the rating agencies', Washington University Law Quarterly 82: 43-95.

International Monetary Fund (IMF) (2010) Financial stability report (October).

International Organization of Securities Commissions (IOSCO) (2003) Statement of principles regarding the activities of credit rating agencies, Madrid.

International Organization of Securities Commissions (IOSCO) (2004) Code of conduct fundamentals for credit rating agencies, Madrid.

International Organization of Securities Commissions (IOSCO) (2007a) Review of implementation of the IOSCO fundamentals of a code of conduct for credit rating agencies, consultation report (February), Madrid.

International Organization of Securities Commissions (IOSCO) (2007b) Review of implementation of the IOSCO fundamentals of a code of conduct for credit rating agencies: Comments received on the consultation report, (May, Madrid).

International Organization of Securities Commissions (IOSCO) (2008a) Report on the subprime crisis (May, Madrid).

International Organization of Securities Commissions (IOSCO) (2008b) Code of conduct fundamentals for credit rating agencies, revised May, Madrid.

International Organization of Securities Commissions (IOSCO) (2011) Regulatory implementation of the statement of principles regarding the activities of credit rating agencies (February, Madrid).

Joint Forum (2009) Stocktaking on the use of credit ratings, (June, Basel).

Mathis, J., McAndrews, J. and Rochet, J.C. (2009) 'Rating the raters: Are reputation concerns powerful enough to discipline rating agencies?', Journal of Monetary Economics 56(5): 657-674.

Pagano, M. and Volpin, P. (2009) Credit rating failures and policy options, CESF Working Paper No. 239, University of Naples.

Partnoy, F. (2001) The paradox of credit ratings, Law and Economics Research Paper No. 20, University of San Diego.

Partnoy, F. (2006) 'How and why credit rating agencies are not like other gatekeepers', in Y. Fuchita and R.E. Litan (eds.) Financial Gatekeepers: Can They Protect Investors? Brookings Institution Press and the Nomura Institute of Capital Markets Research, Washington and Tokyo.

Roland Berger Strategy Consultants (2011) Thumbs up for a European rating agency, press release (27 June). 
Securities and Exchange Commission (SEC) (2008) Summary report of issues identified in the Commission staff's examination of select credit rating agencies (July).

Securities and Exchange Commission (SEC) (2011a) Report on Review of Reliance on Credit Ratings, (July).

Securities and Exchange Commission (SEC) (2011b) Solicitation of comment to assist in a study on assigned credit ratings, Release No. 34-64456; File No. 4-629.

Senate Committee on Governmental Affairs (2002) Financial oversight of Enron: the SEC and private sector watchdogs, Staff Report (7 October).

Skreta, V. and Veldkamp, L. (2009) Ratings shopping and asset complexity: A theory of ratings inflation, NBER Working Paper No 14761.

Swiss Re (2003) Insurance company ratings, sigma 4.

Sy, A.N.R. (2009) The systemic regulation of credit rating agencies and rated markets, IMF Working Paper WP/09/129.

Utzig, S. (2010) The financial crisis and the regulation of credit rating agencies: A European banking perspective, ADBI Working Paper Series No. 188.

White, L.J. (2002) 'The credit rating industry: An industrial organization analysis', in R.M. Levich, G. Manoni and C. Reinhart (eds.) Ratings, Rating Agencies, and the Global Financial System, Kluwer Academic Publishers, New York, pp. 41-64.

White, L.J. (2010) 'The credit rating agencies', Journal of Economic Perspectives 24(2): 211-226.

\section{About the Authors}

Anja Theis is a Senior Economist in the Economics Department of the German Insurance Association (GDV) in Berlin, Germany. Prior to that, she worked in product management at Zurich Deutscher Herold Life Insurance. After graduating in Economics at the University of Konstanz, she obtained her doctorate from the University of Bamberg.

Michael Wolgast is the Chief Economist and Head of the Economics Department at the German Insurance Association (GDV) in Berlin, Germany. Before taking up his current position, he worked as Senior Economist at Deutsche Bank Research in Frankfurt and as an economist for the Federal Ministry of Economic Affairs and for the German Savings Banks' Association in Bonn. He graduated with a maitrise d'économie appliquée from Paris-IX-Dauphine and with a Master's degree in Economics from the London School of Economics and Political Science and took his doctorate at Kiel University. 